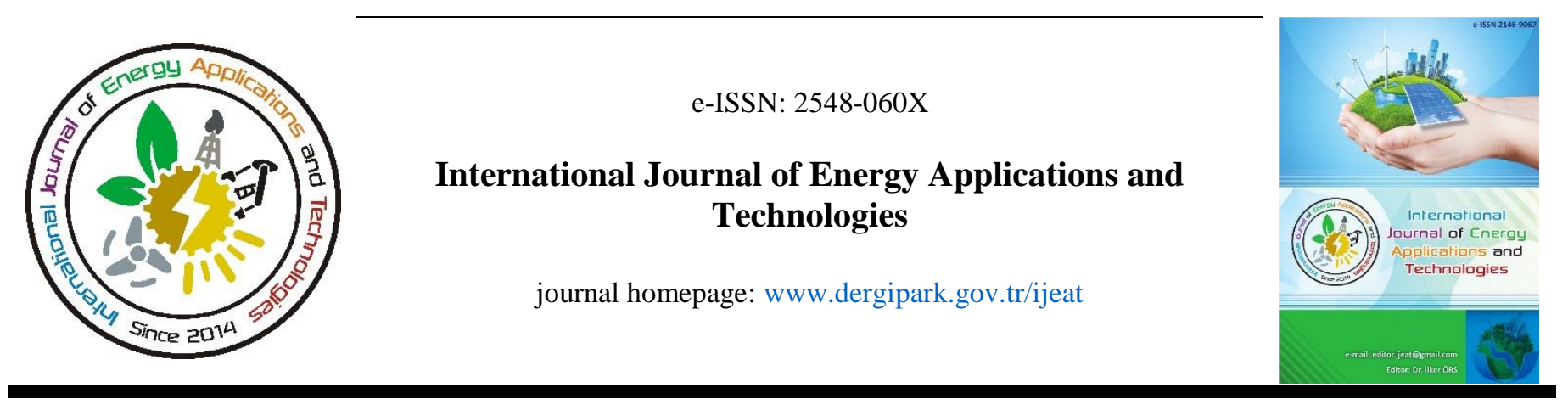

Original Research Article

\title{
The effect of front and rear windscreen angles on the aerodynamic drag force of a simplified car model
}

hosted by Turkish JournalPark

\author{
Mohamed Elrawemi*, Ibrahim Aburawey \\ Mechanical and Industrial Engineering Department, Elmergib University, Alkhoms, Libya
}

\author{
ARTICLE INFO \\ * Corresponding author \\ mselrawemi@elmergib.edu.ly \\ Received August 25, 2019 \\ Accepted December 3, 2019 \\ Published by Editorial Board \\ Members of IJEAT \\ C) This article is distributed by \\ Turk Journal Park System under \\ the $\mathrm{CC} 4.0$ terms and conditions. \\ doi: 10.31593/ijeat.610436
}

\begin{abstract}
Computational fluid dynamic (CFD) is a flow modelling technique which utilizes iterative methods to solve continuity and momentum equations along with any appropriate auxiliary equations depending on the application. This paper studied the effect of front and rear windscreen angles of a car on the drag force for the case of the Citroen C5 2007. Numerical results were obtained based on the finite volume method (FVM). The aerodynamic behavior of the car was studied with different front and rear windscreen angles. The initial results helped to estimate an optimal shape for the car based on the least drag coefficient. Consequently, an optimal car shape is proposed by improving the car's aerodynamic design including the surface roughness and windscreen angles. This has potentially reduced the drag coefficient by $8.88 \%$ compared to the initial design. This would offer a significant opportunity for reducing the fuel consumption.
\end{abstract}

Keywords: Drag Coefficient; Airflow; CFD; FVM; Aerodynamic

\section{Introduction}

To save energy and protect the environment, fuel consumption reduction is a primary concern in the automobile industry [1,2]. In car frame development, the reduction of drag is essential for improving fuel consumption and driving performance [3]. Therefore, understanding of aerodynamic and road loads is very significant in establishing acceleration, braking, stability and fuel consumption characteristics [4]. Aerodynamic drag is the force opposite to the direction of motion that acts on a body moving through air. In the past two decades, CFD has been used widely in vehicle aerodynamic studies [5,6]. Many companies and universities are paying increasing attention to the development of automotive aerodynamics [7,8], where a drag reduction by $2-6 \%$ would result in a significant reduction in fuel consumption [9]. This can be reduced by using active or passive flow control of boundary layer and separation methods, to achieve a delay of separation in the boundary layer $[10,11]$ or by reducing the surface roughness of the car model [12]. Additionally, previous airflow studies revealed that, aerodynamic forces acting on a car can significantly reduce its efficiency $[13,14]$. Nevertheless, if the car shape is redesigned to optimize these forces it could improve results. The main aim of this study is to discover the effect of front and rear windscreen angles of the car shape on the drag force. The aerodynamic behavior of the car was studied with different front and rear windscreen angles, such as $\left(150^{\circ}\right.$ $\left.30^{\circ}\right),\left(150^{\circ}-90^{\circ}\right),\left(90^{\circ}-30^{\circ}\right)$ and $\left(90^{\circ}-90^{\circ}\right)$ in a clockwise direction. The design velocity was varied from $20 \mathrm{~m} / \mathrm{s}$ to 80 $\mathrm{m} / \mathrm{s}$ and acted opposite to the direction of the car motion. The frontal area of the designed car remained constant at $2.83 \mathrm{~m}^{2}$. The work conducted herein was achieved by using two software packages, GAMBIT to develop and design the car shape and FLUENT to investigate the possibility of optimizing the car shape based on the least drag coefficient.

\section{Aerodynamic Forces}

Various forces can affect car performance and stability, these include; motor force, drag force, weight of the car and other 
forces. Among these, only the effect of drag force will be analyzed in this study. The drag force is due to the combined effects of pressure and wall shear forces [15] and defined by Eq. (1).

$$
\mathrm{FD}=1 / 2 C d \rho V^{2} A
$$

Where, $\mathrm{Cd}$ is the drag coefficient, $\rho$ is the density of air, $\mathrm{V}$ is the flow velocity relative to the car, and $\mathrm{A}$ is the frontal area of the car [15]. The power $(\mathrm{P})$ required to overcome this drag is proportional to the cube of the velocity $(\mathrm{V})$ and defined by Eq. (2) [16].

$$
\mathrm{P}=1 / 2 \cdot \rho \cdot \mathrm{CD} \cdot \mathrm{A} \cdot \mathrm{V}^{3}
$$

\section{Numerical Model}

The airflow around the cars is low-speed aerodynamics, thus the airflow field can be regarded as three-dimensional incompressible. The fundamental governing equations for the three-dimensional in-compressible flow are as follows [17]. Continuity equation:

$$
\frac{\partial u_{i}}{\partial x_{i}}=0
$$

Equation of motion:

$$
\frac{\partial\left(\mathrm{u}_{\mathrm{i}} \mathrm{u}_{\mathrm{j}}\right)}{\partial \mathrm{x}_{\mathrm{i}}}=-\frac{\partial \mathrm{p}}{\partial \mathrm{x}_{\mathrm{j}}}+\frac{\partial\left[\mu_{e f f}\left(\frac{\partial \mathrm{u}_{\mathrm{i}}}{\partial \mathrm{x}_{\mathrm{j}}}+\frac{\partial \mathrm{u}_{\mathrm{j}}}{\partial \mathrm{x}_{\mathrm{i}}}\right)\right]}{\partial \mathrm{x}_{\mathrm{j}}}
$$

where $u_{i}$ and $u_{j}$ are the components of the velocity, $x_{i}$ and $x_{j}$ are the coordinates, $p$ is static pressure, $\mu_{\text {eff }}$ is the effective viscosity coefficient of turbulent flow.

\subsection{Geometric model}

The geometric model of the car was constructed by the GAMBIT software package as shown in Figure (1), with dimensions shown in table (1).

Table 1. Specifications of the model

\begin{tabular}{lc}
\hline Length & $4779 \mathrm{~mm}$ \\
Width & $1860 \mathrm{~mm}$ \\
Height & $1451 \mathrm{~mm}$ \\
Ground clearance & $233 \mathrm{~mm}$ \\
Wheel radius & $292 \mathrm{~mm}$ \\
Drag coefficient & 0.3 \\
Fuel tank capacity & $71 \mathrm{liter}$ \\
Maximum speed & $205 \mathrm{~km} / \mathrm{h}$ \\
Fuel consumption & $12.7 / 6.7 / 8.9 \mathrm{l} / 100 \mathrm{~km}$ \\
\hline
\end{tabular}

External volume (domain) has been created around the car, with dimensions as shown in Figure (2). There is a sufficient distance between the front of the car and the domain front to give sufficient clearance upstream and downstream of the car. The purpose of that is to contain distribution of the fluid, to avoid the flow becoming a non-uniform flow and minimize any flow blockage effects to adequately capture turbulent flow behind the car.

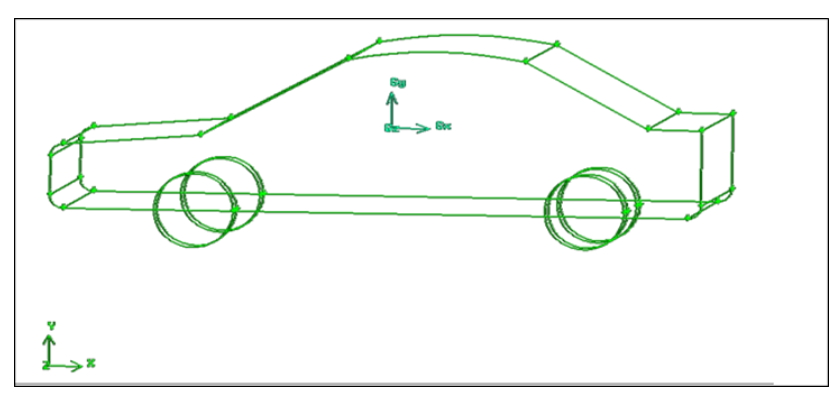

Fig. 1. Schematic representation of a simple car model

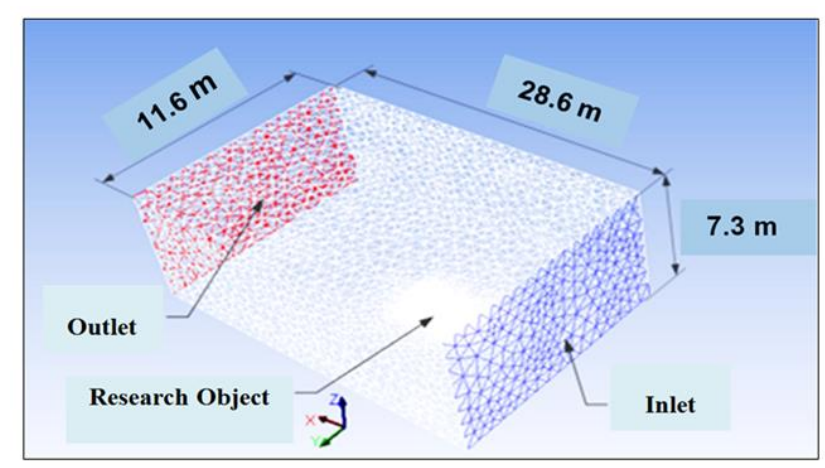

Fig. 2. Computational fluid domain

\subsection{Boundary conditions}

The wind velocity direction will act opposite to the direction of the car motion, accordingly the flow angle in such a case will be $0^{\circ}$ as the velocity has one component in $\mathrm{x}$ direction, since the velocity is parallel to the direction of travel. The settings chosen for this study were listed in Table 2.

Table 2. Boundary conditions

\begin{tabular}{cc}
\hline Boundary & Type \\
\hline Domain-front & Velocity inlet $(20,50,80 \mathrm{~m} / \mathrm{s})$ \\
Domain-back & Pressure outlet \\
Domain (right, left and top) & Stationary wall \\
Domain-bottom (road) & Moving wall $(\mathrm{V}=20,50,80 \mathrm{~m} / \mathrm{s})$ \\
Car body & No slip-stationary wall \\
Car wheels & Rotational wall \\
\hline
\end{tabular}

The material in the volume (domain) was defined as a fluid (air) using the 'continuum types' section and considered as three-dimensional in-compressible flow with density of $1.225 \mathrm{~kg} / \mathrm{m}^{3}$. Once all the prior steps were completed successfully, the four models of the designed cars were meshed to manage the setting up of the problem in the FLUENT software package.

\subsection{Meshing}

A suitable mesh will give meaningful and accurate results. In this study, the area of interest (car) was relatively refine, and that near the domain was relatively coarse. For complex geometry like this car, it is very difficult to fit a square in each corner, therefore triangular mesh elements rather than quadrilateral ones were used. The flow domain was 
discretized into approximately 166032 tetrahedral elements as shown in Figure (3). Skewness of 0.67 quality was achieved for about $96.35 \%$ of the elements.

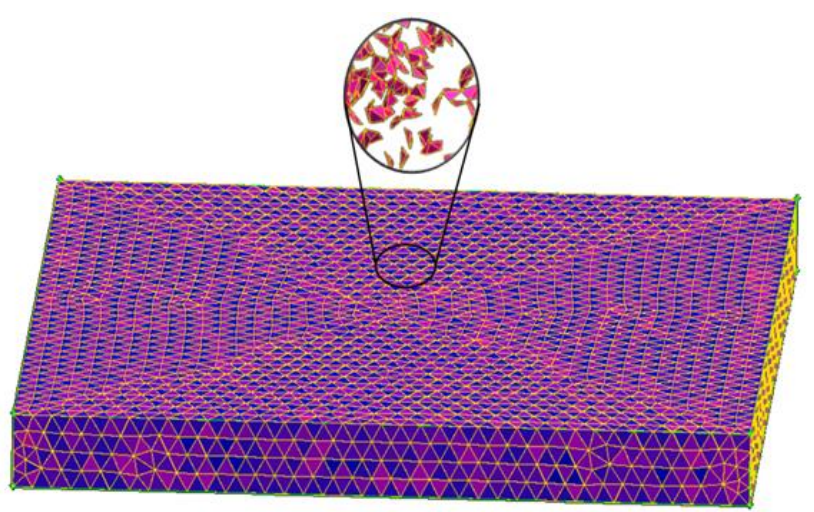

Fig. 3. Meshing the car model

\section{Simulation Procedure}

The simulation has been conducted three times at a range wind velocity of $(20,50$ and $80 \mathrm{~m} / \mathrm{s})$ for each car model in order to understand the relationship between the free stream velocity and the drag force. The simulation continued until the solution converged at roughly 190 iterations as shown in Figure (4), where the useful data can be extracted and analyzed. The scaled residual is shown in the following figure.

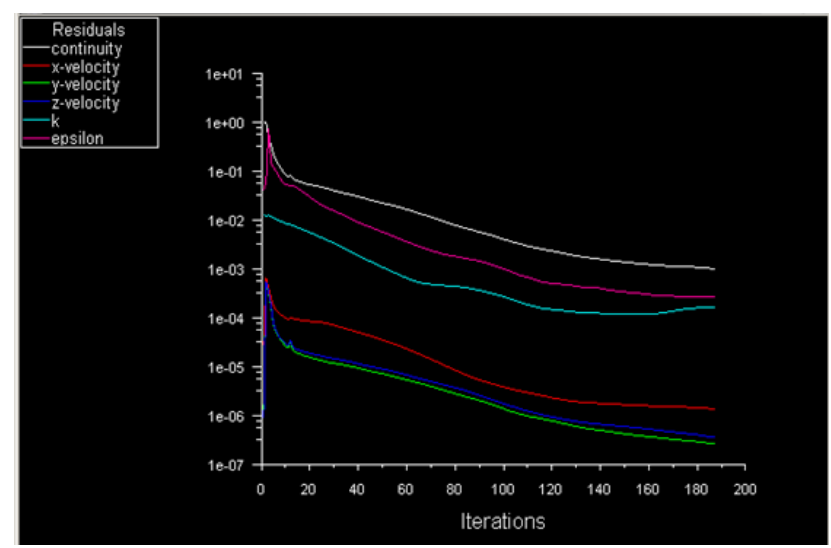

Fig. 4. Scaled residual of the simulation

\section{Results Discussion}

The air can be considered as a series of thin layers, subsequently when the air flow remains in the layers that means the flow is laminar and the drag which is acting on the car body is very low. However, when the flow separates from the car body and becomes turbulent, the drag will increase significantly, so it is essential to have no flow separation at any point when the car is redesigned. This can be achieved by modifying the sharp edges of the car into fillet to reduce the resistance of the air. Figure (5) show that the streamlines started to deflect at the top of the car, therefore, the velocity will start to increase due to the pressure ingredient dropping accordingly.

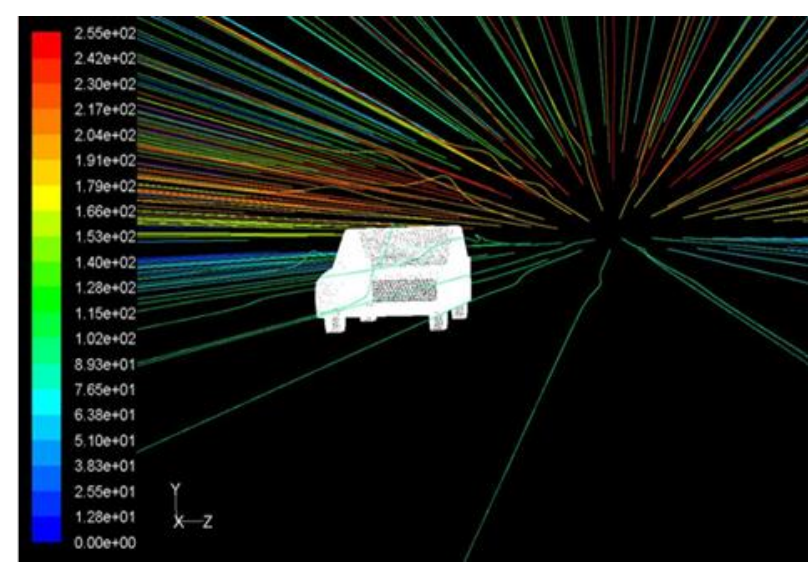

Fig. 5. Path lines around the car

In the following figure (6) the frontal area of the car has a greater pressure effect than other areas, particularly when the windscreen angle was changed to $90^{\circ}$ (Model $\mathrm{C}$ and Model D). Hence by improving the design of the frontal area of the car (windscreen), the impact of pressure on the car will be clearly reduced. In addition, when the car moves forward, a low pressure zone is created behind the car. This low pressure zone pulls the car from behind opposite to its direction of movement and creates a pressure drag. This low pressure zone is created due to the separation of flow and consequent vortices are generated at the back of the car.
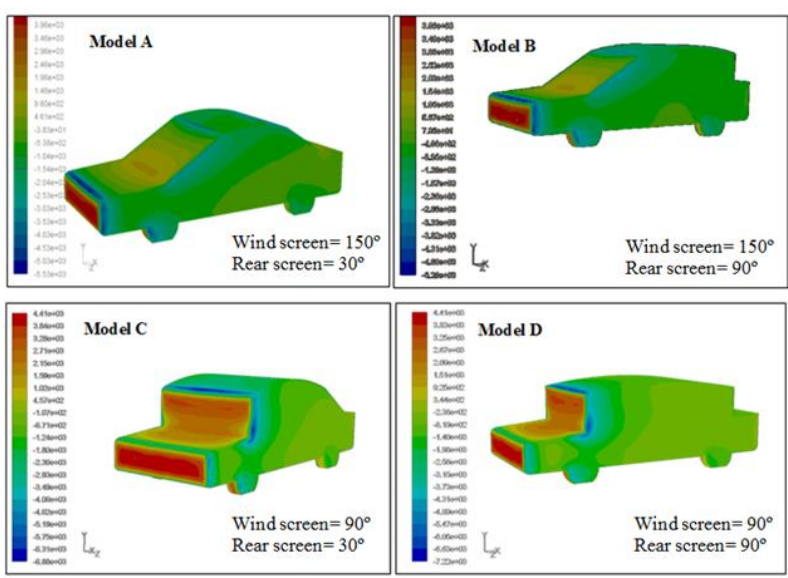

Fig. 6. Contours of static pressure for the baseline of the car models

Plotting the 12 simulations (4 models at 3 velocities, 20, 50 and $80 \mathrm{~m} / \mathrm{s}$ ) in one graph as shown in Figure (7), the effects of changing the front and the rear windscreen angles can be clearly explained in a few points. Changing the rearscreen angle from $30^{\circ}$ to $90^{\circ}$ (model B) did not affect the drag force at a velocity of $20 \mathrm{~m} / \mathrm{s}$. However, when the velocity started to increase, the drag force increased slightly. Comparing the changes of the windscreen from $150^{\circ}$ to $90^{\circ}$ with the rear windscreen angle at $30^{\circ}$ (model $\mathrm{C}$ ), there is a dramatic increase in the drag force. This is since having the windscreen at $90^{\circ}$ will cause the flow to act perpendicularly to it, resulting in high pressure on the frontal area of the car and the front windscreen. This will then increase the drag force 
and the drag coefficient, resulting in a high ratio of fuel consumption as stated in $\mathrm{Eq}(2)$.

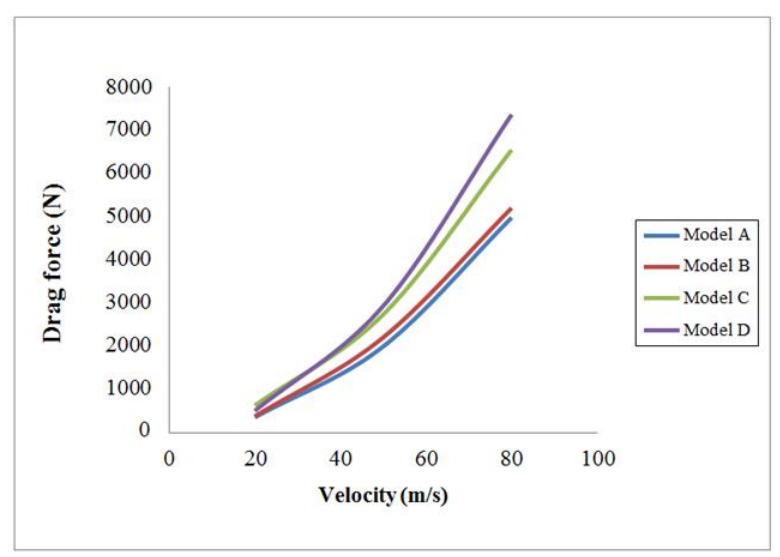

Fig. 7. Aerodynamic force as a function of the front and rear windscreen angle

For the last simulation (model D), when the front screen and the rear screen angles are at $90^{\circ}$, the drag force increased dramatically because of the wind direction, which act opposite to the car direction. Furthermore, the drag coefficient doubles to over 0.6 at $80 \mathrm{~m} / \mathrm{sec}$ as shown in Figure (8). This is due to the shape of the car being changed completely, as compared with the real car shape.

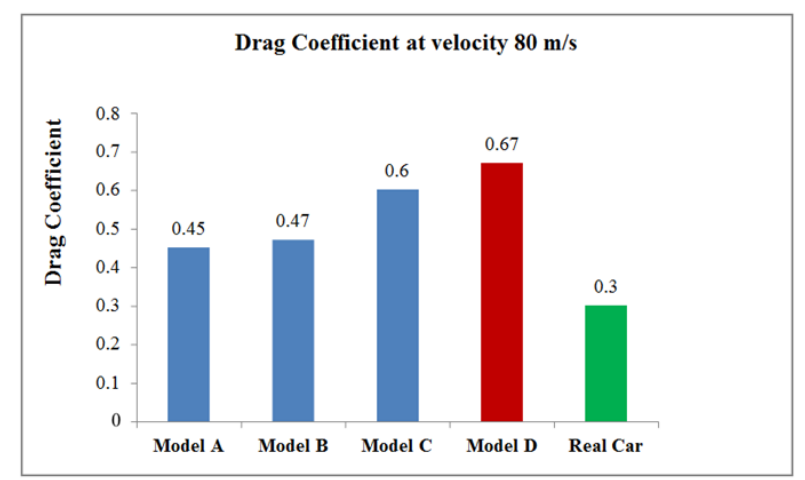

Fig. 8. Computational of drag coefficients

\section{Optimization}

Car drag reduction is a major topic in the automobile industry, because of its close links with reducing fuel consumption, stability and handling of the car particularly at high speeds $[18,19]$. Flow separation and reattachment points can play a very important role on the drag force and drag coefficient reduction. Accordingly, the car body must be designed to ensure that the separation will not happen at any point or does occur, must reattach as quickly as possible. This may happen due to increasing the windscreen angle where the separation will happen early and the reattachment point will move away. When the airflow interacts with the front of the car and the boundary layer are still laminar. However, after a certain distance the flow particles will start to separate at a point on the bonnet or at the back of the car body. This occurs due to changing the particles' direction of motion as they lose momentum and the flow starts to become turbulent, so if these particles are very close to the car face they will stop moving and the velocity gradient will be zero at that point as well as the shear stress. Thus, $\partial \mathrm{u} / \partial \mathrm{y}=0$ will represent a condition when separation starts to take place.

The present work in this section aims to develop and propose a simplified shape of the basic car model. There will be a minor change with respect to two geometrical angles (windscreen and rear screen angles) with a fixed frontal area of $2.83 \mathrm{~m}^{2}$. The objective of these modifications is to reduce the total drag coefficient of the car.

As shown in Figure (8) decreasing the windscreen and increasing the rear screen resulted in a high drag coefficient. Hence, the windscreen angle in this case will be increased slightly from $\left(150^{\circ}\right.$ into $\left.155^{\circ}\right)$ in a clockwise direction and the rear screen angle will be decreased from $\left(30^{\circ}\right.$ to $\left.25^{\circ}\right)$ in a clockwise direction. In addition, the fillet tool was used between the edges of the car faces to obtain a smoother flow on the car body, avoid the surface roughness and so there was no flow separation or if the flow happens, it should reattach as quickly as possible. Mesh, domain dimension, boundary conditions and steps of the simulation are the same as the earlier simulations.

\subsection{Pressure distribution and path lines}

The figure below shows much more improvement in the pressure distribution on the car body compared with previous simulations, where the pressure value on the front face of the car decreased to $3.78 \mathrm{e}^{3} \mathrm{~Pa}$ at a velocity of $80 \mathrm{~m} / \mathrm{s}$. As shown, the frontal area of the car experiences significantly higher pressure than the rest of the car, this can be attributed to the poor curvature.

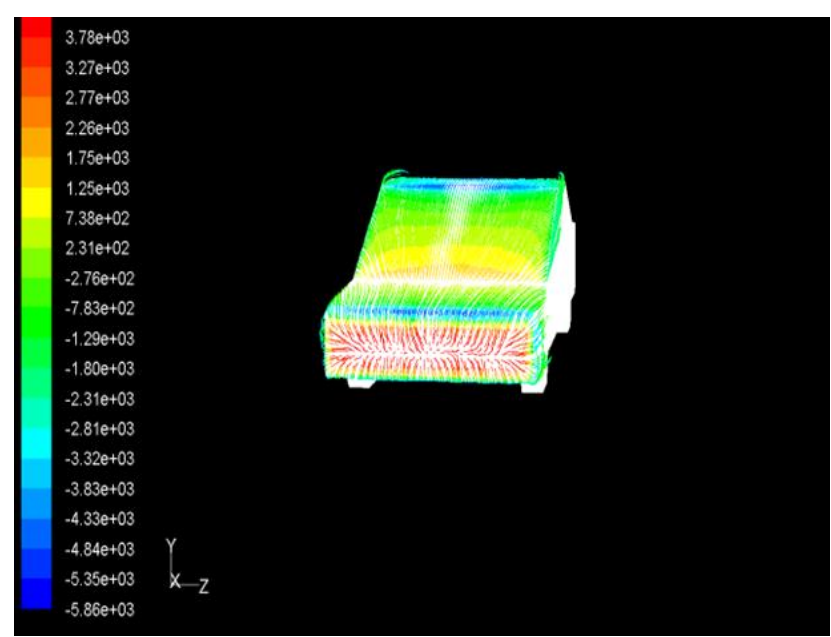

Fig. 9. Pressure distribution and path lines of the proposed car model Based on the simulation, the drag coefficient decreased slightly for this car shape compared to other car models, the simulation has been done at three different velocities $(20 \mathrm{~m} / \mathrm{s}$, 
$50 \mathrm{~m} / \mathrm{s}$ and $80 \mathrm{~m} / \mathrm{s})$. The improvements which have been obtained for this proposed car shape are compared with others in the following figure.

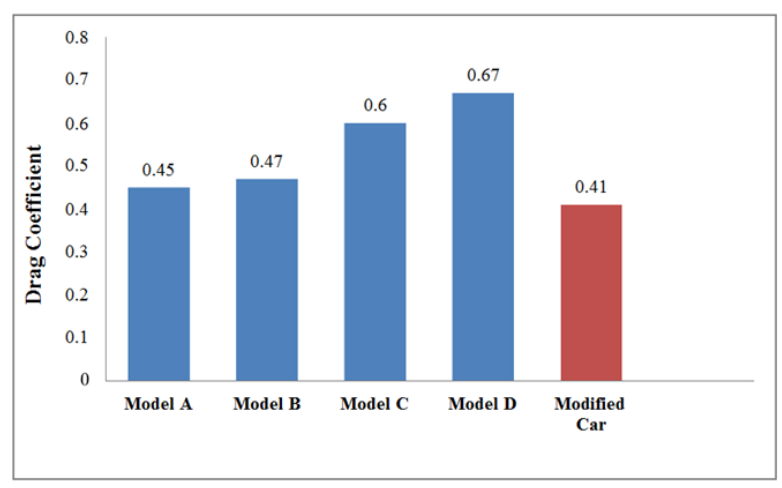

Fig. 10. Modified car drag coefficients at a velocity of $80 \mathrm{~m} / \mathrm{s}$

As can be seen there is a minor improvement in the aerodynamic drag coefficient for the modified car shape, compared with the others. The drag coefficient reduced to 0.41 at a velocity of $80 \mathrm{~m} / \mathrm{s}$ which is quite a reasonable value when compared to the real car drag coefficient, also a reduction of $6.36 \%$ of the drag force acting on the car was achieved. This is due to the surface finish, curves are so smooth thus streamlines are attached to the surface, it flows smoothly over the surface, creating a minimum drag.

\section{Conclusion}

The overall investigation in this research paper highlights the importance of the front and the rear windscreen angle design and the surface roughness of the car shape, which have significant effects on keeping the flow attached to the car body as much as possible. The aerodynamic drag coefficient of the modified car model is reduced to 0.41 , which is about $8.88 \%$ less than the initial car design. This would result in a significant reduction in fuel consumption.

In conclusion, despite the absence of accurate drag prediction for CFD analysis the overall investigation proves that CFD is an extremely powerful tool in analyzing and calculating forces and flow visualization measurements. Authors of this research paper recommend a further experimental validation method for the simulation carried out herein using a small scale model (prototype) of the vehicle to be tested in a wind tunnel.

\section{References}

[1] Hassan, S. R., Islam, T., Ali, M., \& Islam, M. Q. (2014). Numerical study on aerodynamic drag reduction of racing cars. Procedia Engineering, 90, 308-313.

[2] Guilmineau, E. (2008). Computational study of flow around a simplified car body. Journal of wind engineering and industrial aerodynamics, 96(6-7), 1207-1217.
[3] Mohamed-Kassim, Z., \& Filippone, A. (2010). Fuel savings on a heavy vehicle via aerodynamic drag reduction. Transportation Research Part D: Transport and Environment, 15(5), 275-284.

[4] Kim, J. J., Hong, J., \& Lee, S. J. (2017). Bio-inspired cab-roof fairing of heavy vehicles for enhancing drag reduction and driving stability. International Journal of Mechanical Sciences, 131, 868-879.

[5] Raveendran, A., Sridhara, S. N., Rakesh, D., \& Shankapal, S. R. (2009). Exterior styling of an intercity transport bus for improved aerodynamic performance (No. 2009-28-0060). SAE Technical Paper.

[6] Buil, R. M., \& Herrer, L. C. (2009). Aerodynamic analysis of a vehicle tanker. Journal of Fluids Engineering, 131(4), 041204.

[7] Gu, Z. Q., \& He, G. M. (2014). Analysis on the driving stability of high-speed container truck in crosswinds. Trans Beijing Inst Technol, 34, 250-254.

[8] Singh, S. N., Rai, L., Puri, P., \& Bhatnagar, A. (2005). Effect of moving surface on the aerodynamic drag of road vehicles. Proceedings of the Institution of Mechanical Engineers, Part D: Journal of Automobile Engineering, 219(2), 127-134.

[9] Bayındırlı, C . (2019). Drag reduction of a bus model by passive flow canal. International Journal of Energy Applications and Technologies, 6 (1), 24-30. DOI: 10.31593/ijeat.533745

[10] Bruneau, C. H., Creusé, E., Depeyras, D., Gilliéron, P., \& Mortazavi, I. (2010). Coupling active and passive techniques to control the flow past the square back Ahmed body. Computers \& Fluids, 39(10), 1875-1892.

[11] Krajnović, S., \& Fernandes, J. (2011). Numerical simulation of the flow around a simplified vehicle model with active flow control. International Journal of Heat and Fluid Flow, 32(1), 192-200.

[12] Hassan, S. R., Islam, T., Ali, M., \& Islam, M. Q. (2014). Numerical study on aerodynamic drag reduction of racing cars. Procedia Engineering, 90, 308-313.

[13] Bijlani, B., Rathod, P., \& Sorthiya, A. (2013). Experimental investigation of aerodynamic forces on sedan, fastback and square-back car by simulation in CFD Review Study. Int J Emerg Technol Adv Eng, 3(2), 346349.

[14] Usherwood, J. R., \& Lehmann, F. O. (2008). Phasing of dragonfly wings can improve aerodynamic efficiency by removing swirl. Journal of The Royal Society Interface, 5(28), 1303-1307.

[15] Yunus, A. C. (2010). Fluid Mechanics: Fundamentals And Applications (Si Units). Tata McGraw Hill Education Private Limited.

[16] Malviya, Vihar, Mishra, Rakesh and Fieldhouse, John D. (2008) Comparative computational analysis of 
drag $\neg$ reducing devices for tractor trailers. In: Proceedings of Computing and Engineering Annual Researchers' Conference 2008: CEARC'08. University of Huddersfield, Huddersfield, pp. $1 \neg 8$. ISBN $978 \neg 1 \neg 86218 \neg 067 \neg 3$.

[17] Yuan, Z., \& Wang, Y. (2017). Effect of underbody structure on aerodynamic drag and optimization. Journal of Measurements in Engineering, 5(3), 194-204.

[18] Guo, Z., Zhang, Y., \& Ding, W. (2019). Optimization of the aerodynamic drag reduction of a passenger hatchback car. Proceedings of the Institution of Mechanical Engineers, Part G: Journal of Aerospace Engineering, 233(8), 2819-2836.

[19] Khondge, A. D., Sovani, S., \& Verma, G. (2011). Automation of vehicle aerodynamic shape exploration and optimization using integrated mesh morphing and CFD (No. 2011-01- 0170). SAE Technical Paper. 